First publ. in: The Journal of Membrane Biology 179 (2001), pp. 263-273

\title{
Ion Selectivity of the Cytoplasmic Binding Sites of the Na,K-ATPase: II. Competition of Various Cations
}

\author{
A. Schneeberger, H.-J. Apell \\ Department of Biology, University of Konstanz, Fach M635, D-78457 Konstanz, Germany
}

Received: 7 August 2000/Revised: 14 November 2000

\begin{abstract}
In the $\mathrm{E}_{1}$ state of the $\mathrm{Na}, \mathrm{K}-\mathrm{ATPase}$ all cations present in the cytoplasm compete for the ion binding sites. The mutual effects of mono-, di- and trivalent cations were investigated by experiments with the electrochromic fluorescent dye RH421. Three sites with significantly different properties could be identified. The most unspecific binding site is able to bind all cations, independent of their valence and size. The large organic cation $\mathrm{Br}_{2}-\mathrm{Titu}^{3+}$ is bound with the highest affinity $(<\mu \mathrm{M})$, among the tested divalent cations $\mathrm{Ca}^{2+}$ binds the strongest, and $\mathrm{Na}^{+}$binds with about the same equilibrium dissociation constant as $\mathrm{Mg}^{2+}(\sim 0.8 \mathrm{~mm})$. For alkali ions it exhibits binding affinities following the order of $\mathrm{Rb}^{+} \simeq$ $\mathrm{K}^{+}>\mathrm{Na}^{+}>\mathrm{Cs}^{+}>\mathrm{Li}^{+}$. The second type of binding site is specific for monovalent cations, its binding affinity is higher than that of the first type, for $\mathrm{Na}^{+}$ions the equilibrium dissociation constant is $<0.01 \mathrm{~mm}$. Since binding to that site is not electrogenic it has to be close to the cytoplasmic surface. The third site is specific for $\mathrm{Na}^{+}$, no other ions were found to bind, the binding is electrogenic and the equilibrium dissociation constant is 0.2 mM.
\end{abstract}

Key words: Sodium pump - Cytoplasmic ion binding - Electrochromic fluorescent dye - Ion transport Monovalent ions - Magnesium effects

\section{Introduction}

The Na,K-ATPase is an integral plasma membrane protein of (virtually) all animal cells that employs the free energy derived from the hydrolysis of ATP to actively transport $\mathrm{Na}^{+}$and $\mathrm{K}^{+}$ions against their electrochemical

Correspondence to: H.-J. Apell potential gradients in a Ping-Pong type mechanism [20, $22]$. During the recent years the transport cycle [1, 3, 27] has been broken down into a series of defined reaction steps and their kinetic properties were investigated and characterized $[5,10,11,15,17,40]$. In the case of the sodium transport branch the reaction sequence,

$$
\begin{aligned}
3 \mathrm{Na}^{+}{ }_{\text {cyt }} & +\mathrm{E}_{1} \rightarrow \mathrm{Na}_{3} \mathrm{E}_{1} \rightarrow\left(\mathrm{Na}_{3}\right) \mathrm{E}_{1}-\mathrm{P} \rightarrow \\
& \mathrm{P}-\mathrm{E}_{2}\left(\mathrm{Na}_{3}\right) \rightarrow \mathrm{P}-\mathrm{E}_{2}\left(\mathrm{Na}_{2}\right)+\mathrm{Na}^{+} \rightarrow \mathrm{P}-\mathrm{E}_{2} \\
& +\mathrm{Na}^{+}{ }_{\text {ext }},
\end{aligned}
$$

is able to explain all experimental data available. $\mathrm{Na}^{+}$ occlusion and enzyme phosphorylation as well as the conformational transition $\mathrm{E}_{1}$ to $\mathrm{E}_{2}$ and ion release to the extracellular side of the membrane were extensively studied $[2,6,15-17,40]$. However, the properties of the cytoplasmic ion-binding sites, sodium binding and the competition of various cations at these sites as well as the nature and structure of these sites are only poorly understood so far. Recently, the electrogenicity of cytoplasmic $\mathrm{Na}^{+}$binding (in contrast to all other ions) was proven $[12,26,32]$ and it was shown that the electrogenic binding of the third $\mathrm{Na}^{+}$ion to its (uncharged) site triggers a conformational rearrangement at the ATP-binding site which makes the enzyme competent to be phosphorylated, the next step in the transport cycle [30]. In forward direction three $\mathrm{Na}^{+}$ions are necessary for the phosphorylation of the enzyme, and no other ions may replace $\mathrm{Na}^{+}$. In the second half of the physiological transport cycle $2 \mathrm{~K}^{+}$ions are transferred into the cytoplasm, however, it has been shown that a number of congeners, almost all monovalent cations, may replace $\mathrm{K}^{+}$. In addition, these ions allow by binding at the cytoplasmic side the so-called backdoor phosphorylation by inorganic phosphate $[8,28]$

$\mathrm{E}_{1}+2 \mathrm{X}_{c y t}^{+} \rightarrow \mathrm{X}_{2} \mathrm{E}_{1} \rightarrow \mathrm{E}_{2}\left(\mathrm{X}_{2}\right) \rightarrow \mathrm{P}^{-\mathrm{E}_{2}} \mathrm{X}_{2}$. 
$\mathrm{X}^{+}$may be $\mathrm{K}^{+}, \mathrm{Li}^{+}, \mathrm{Rb}^{+}, \mathrm{Cs}^{+}, \mathrm{NH}_{4}^{+}, \mathrm{Tl}^{+}$or $\mathrm{H}^{+}[4,14$, 23]. This observation indicates that these ions are able to bind to the cytoplasmic ion binding sites, and therefore compete with $\mathrm{Na}^{+}$for the sites when they are present simultaneously. But it is also known that the presence of divalent or trivalent cations affects $\mathrm{Na}^{+}$binding in terms of modified apparent affinities of $\mathrm{Na}^{+}$binding $[15,18$, 33]. A previously developed fluorescence method, using the electrochromic styryl dye RH421 [7], could be successfully applied to detect the electrogenic binding of the third $\mathrm{Na}^{+}$ion, the only reaction step which was found to produce a reliable response with respect to cytoplasmic ion binding or release [30]. Therefore, an experimental concept has been developed to utilize this single detectable reaction step as a monitor to investigate interaction between and competition of various ions at the cytoplasmic sites.

The aim of this presentation was to elucidate the interaction or competition mechanisms of cations of variable valence with respect to their binding to the ion sites of the Na,K-ATPase and to identify constraints on possible structural characteristics of the ion binding sites.

\section{Materials and Methods}

Sodium dodecylsulfate (SDS) was obtained from Pierce Chemical. Phosphoenolpyruvate, pyruvate kinase, lactate dehydrogenase, NADH and ATP (disodium salt, special quality) were from Boehringer, Mannheim. The fluorescent dyes RH421 and FITC were from Molecular Probes, Eugene, OR. Dye purity was checked by thin-layer chromatography. All other reagents were the highest grade commercially available.

$\mathrm{Na}, \mathrm{K}-\mathrm{ATPase}$ was prepared from the outer medulla of rabbit kidneys in the form of open membrane fragments using procedure $\mathrm{C}$ of Jørgensen [19]. Protein concentration was assessed by the Lowry method, using bovine serum albumin as a standard. Specific ATPase activity was determined by the pyruvate kinase/lactate dehydrogenase assay [34]. The specific activity was in the range of 1900 to $2300 \mu \mathrm{M}$ $\mathrm{P}_{i}$ per $\mathrm{mg}$ protein and $\mathrm{h}$ at $37^{\circ} \mathrm{C}$. Trypsin-digested protein, the socalled $19 \mathrm{kDa}$ membranes, was prepared according to Capasso et al. [9, 35].

Fluorescence measurements were carried out in a Perkin-Elmer LS 50B fluorescence spectrophotometer as described in the recently published part I of this paper [30]. The excitation wavelength was set to $580 \mathrm{~nm}$ and the emission wavelength to $650 \mathrm{~nm}$ (slit width $15 \mathrm{~nm}$ and $20 \mathrm{~nm}$, respectively). Equilibrium titration experiments were performed in standard buffer containing $25 \mathrm{~mm}$ histidine, 0 or $0.5 \mathrm{~mm}$ EDTA, pH 7.2. (In some experiments a high ionic strength of the buffer was chosen by addition of $300 \mathrm{~mm}$ choline chloride to check for fluorophore artifacts. No significant differences were found.) $200 \mathrm{nM}$ RH421 and 9-10 $\mu \mathrm{g} / \mathrm{ml}$ of membrane fragments containing $\mathrm{Na}, \mathrm{K}-$ ATPase were added to the thermostated cuvette and equilibrated until a stable fluorescence signal, $F_{0}$, was obtained. Titrations were carried out by adding small aliquots of the indicated salt solutions from various concentrated stocks until no further changes of fluorescence could be observed. To allow a comparison between different titration experiments relative fluorescence changes, $\Delta F / F_{0}=\left(F-F_{0}\right) / F_{0}$, were calculated (in \%) with respect to $F_{0}$. Specific fluorescence levels could be assigned to defined states in the pump cycle of the Na,K-ATPase [15]. All experiments were performed at $16 \pm 0.5^{\circ} \mathrm{C}$.

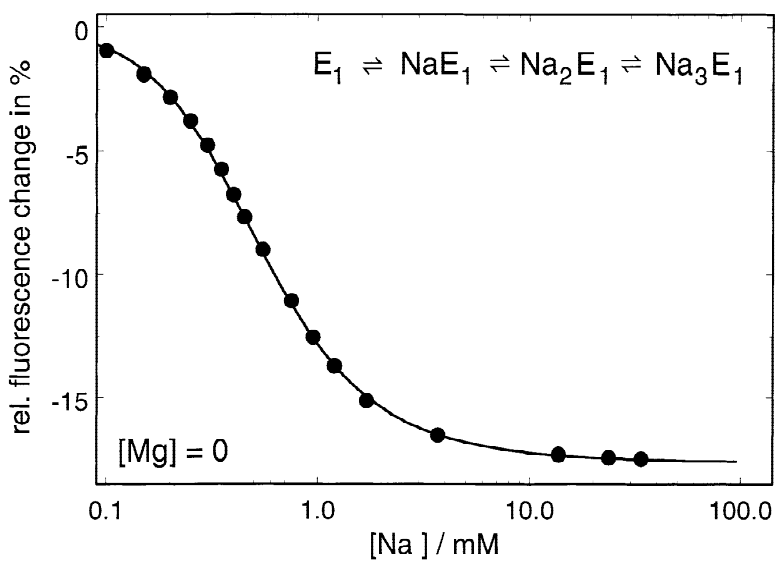

Fig. 1. Electrogenic binding of $\mathrm{Na}^{+}$in state $\mathrm{E}_{1}$ of the $\mathrm{Na}, \mathrm{K}-\mathrm{ATPa}$ detected by RH421. The standard buffer (see Materials and Methods) contained $300 \mathrm{~mm}$ choline chloride and no $\mathrm{Mg}^{2+}$ ions. The line through the data points is a fit according to the mathematical representation of the sequential reaction scheme inserted with the equilibrium dissociation constants $K_{1}^{\mathrm{Na}}=0.005 \mathrm{mM}, K_{2}^{\mathrm{Na}}=0.85 \mathrm{mM}, K_{3}^{\mathrm{Na}}=0.25 \mathrm{mM}$ (see text).

\section{AbBreviations}

The abbreviations used are: RH421: N-(4-sulfobutyl)-4-[4-(pdipentylaminophenyl)butadienyl]-pyridinium, inner salt; $\mathrm{Br}_{2}-\mathrm{Titu}^{3+}$ : 1,3-dibromo-2,4,6-tris (methylisothiouronium) benzene; FITC: fluorescein 5-isothiocyanate (Isomer I).

\section{Results}

Binding of cations to the cytoplasmic sites of the Na,KATPase was investigated by the RH421 method. Since only $\mathrm{Na}^{+}$ions bind electrogenically in the $\mathrm{E}_{1}$ conformation of the ion pump $[12,30]$, all ions other than $\mathrm{Na}^{+}$ should have only a marginal effect on the fluorescence intensity $\left(\Delta F_{\max } / F_{0}<3 \%\right)$. In the following it will be shown that this is true for all other monovalent cations, however, some di- and trivalent cations are able to affect the fluorescence intensity of the styryl dye. Competitive interactions at the cytoplasmic sites between $\mathrm{Na}^{+}$and any other cation species may be used to study not only their mutual effect but also to determine binding affinities on the basis of reaction schemes presented in the following. The concentration-dependent RH421 fluorescence change as the principally detected process is shown in Fig. 1, where in the absence of $\mathrm{Mg}^{2+}$ ions the cooperative $\mathrm{Na}^{+}$binding to the $\mathrm{E}_{1}$ state of the $\mathrm{Na}, \mathrm{K}$-ATPase is shown. By numerous titration experiments the dependence of the RH421 fluorescence on $\mathrm{Na}^{+}$concentration was determined and analyzed according to the reaction sequence $\mathrm{E}_{1} \rightleftharpoons \mathrm{NaE}_{1} \rightleftharpoons \mathrm{Na}_{2} \mathrm{E}_{1} \rightleftharpoons \mathrm{Na}_{3} \mathrm{E}_{1}$. Since the maximum fluorescence decrease, $\Delta F / F_{0}\left(\left[\mathrm{Na}^{+}\right] \rightarrow \infty\right)$ can be measured independently, a fit of the numerical representation of the indicated reaction scheme to the 
data depends only on the three equilibrium dissociation constants. The determined constants were $K_{1}^{\mathrm{Na}}<0.01$ $\mathrm{mM}, K_{2}^{\mathrm{Na}}=0.86 \pm 0.13 \mathrm{~mm}, K_{3}^{\mathrm{Na}}=0.3 \pm 0.07 \mathrm{mM}$. It is remarkable that the third binding site has a higher binding affinity than the second one (see Discussion).

\section{Antagonistic EfFects of Monovalent Ions with RESPECT TO $\mathrm{Na}^{+}$}

$\mathrm{K}^{+}$ions are the physiological counter ions to $\mathrm{Na}^{+}$in the transport cycle. Alkali metal ions, such as $\mathrm{Li}^{+}, \mathrm{Rb}^{+}, \mathrm{Cs}^{+}$ and others "congeners" of $\mathrm{K}^{+}$, are also transported by the $\mathrm{Na}, \mathrm{K}-\mathrm{ATPase}$. Consequently, they are able to bind to the $\mathrm{Na}, \mathrm{K}-\mathrm{ATPase}$ in its $\mathrm{E}_{1}$ conformation. When two of these ions are bound they induce in the absence of ATP a conformational transition into an occluded state of $E_{2}$. This reaction step was widely used to determine the occlusion capacity of the ion pump by the respective radioactive isotopes of the alkali ions. The binding process itself could not be detected by this method.

To investigate the antagonistic effect between $\mathrm{Na}^{+}$ and other monovalent cations, two different, complementary approaches may be used: In the absence of other cations but a fixed concentration of a competing ion $\left(\mathrm{K}^{+}\right.$ or one of its congeners $\mathrm{Li}^{+}, \mathrm{Rb}^{+}$, and $\mathrm{Cs}^{+}$) binding of $\mathrm{Na}^{+}$ is studied by a stepwise increase of the $\mathrm{Na}^{+}$concentration until the saturation of the Na-specific fluorescence decrease is reached. Alternatively, first $\mathrm{Na}^{+}$is added up to concentrations at which a saturating fluorescence decrease is obtained, and then by increasing the concentration of $\mathrm{K}^{+}$or one of the congeners the fluorescence decrease is reversed. The concentration dependence of the relative fluorescence intensity could be fitted by the Hill function

$$
\frac{\Delta F(c)}{F_{0}}=\Delta F_{\max } \cdot \frac{1}{1+\left(\frac{K_{M}}{c}\right)^{n \mathrm{H}}}
$$

Experiments of the second type are presented in the following (Fig. 2). To a cuvette with $1 \mathrm{ml}$ of standard buffer $200 \mathrm{~nm} \mathrm{RH} 421$ and $9 \mu \mathrm{g} / \mathrm{ml}$ membrane fragments were added and the fluorescence intensity was traced until a steady-state level was reached. The presence of $0.5 \mathrm{~mm}$ EDTA ensure that no traces of $\mathrm{Mg}^{2+}$ or other divalent cations were present. Addition of $3 \mathrm{~mm} \mathrm{NaCl}$ provided a $\mathrm{Na}^{+}$concentration high enough to almost saturate the ion binding sites of the Na,K-ATPase $(>5 \times$ $K_{1 / 2}^{\mathrm{Na}}$ ) and to produce predominantly the state $\mathrm{Na}_{3} \mathrm{E}_{1}$. Successive additions of $\mathrm{CsCl}$ in aliquots between 1 and $50 \mathrm{~mm}$ produced a titration of the fluorescence as shown in Fig. $2 A$. The relative fluorescence changes, $\Delta F / F_{0}$, with respect to the level before addition of $\mathrm{Na}^{+}$, were plotted against the corresponding concentration of $\mathrm{Cs}^{+}$as shown in Fig. 2B. The same experiments were also per-
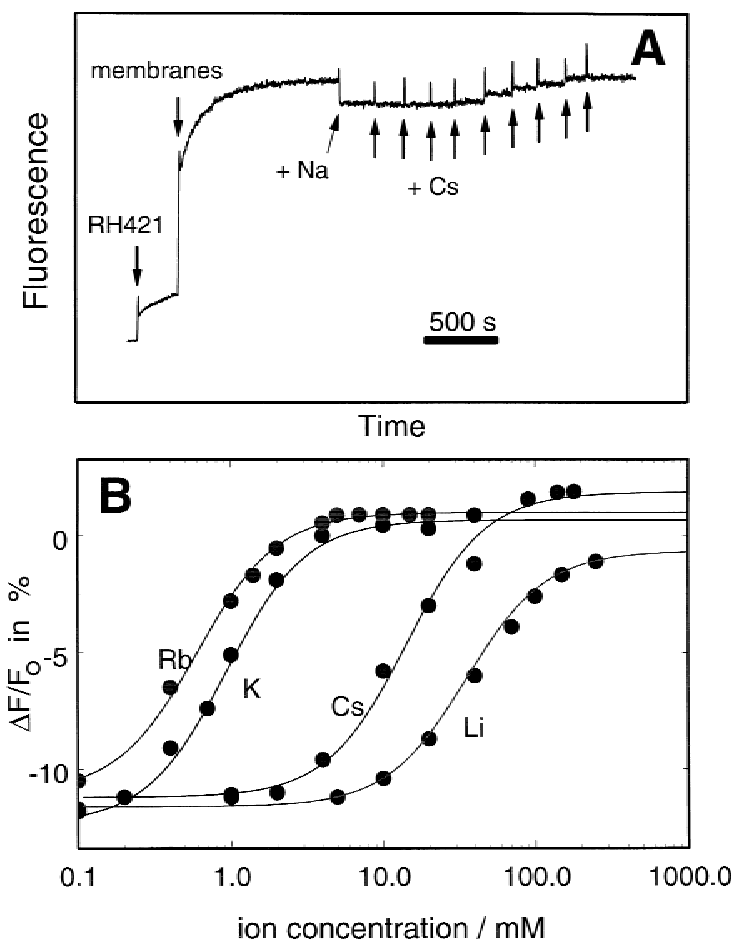

Fig. 2. Antagonistic effect of alkali ion binding in state $E_{1}$ of the $\mathrm{Na}, \mathrm{K}-\mathrm{ATPase}$ detected by RH421 fluorescence changes. (A) Original fluorescence trace of a $\mathrm{Cs}^{+}$titration experiment starting from state $\mathrm{Na}_{3} \mathrm{E}_{1}$ in which the ion binding sites were virtually saturated with $\mathrm{Na}^{+}$. This state is visible by the fluorescence decrease of about $12 \%$ upon addition of $3 \mathrm{~mm} \mathrm{NaCl}$ ("+ $\mathrm{Na").} \mathrm{The} \mathrm{final} \mathrm{Cs}^{+}$concentration was 190 mM. (B) Representation of the analyses of titration experiments similar to that shown in panel A performed with the alkali ions, $\mathrm{Rb}^{+}, \mathrm{K}^{+}, \mathrm{Cs}^{+}$, and $\mathrm{Li}^{+}$, in form of a semilogarithmic Hill-plot. A shift of the halfsaturating ion concentration to higher values indicates an apparently reduced binding affinity. The data were fitted by Eq. (1) with a Hill coefficient, $n_{\mathrm{H}}$, of 1.62 for all ions and with half-saturating ion concentrations of $K_{1 / 2}\left(\mathrm{Rb}^{+}\right)=0.7 \pm 0.07 \mathrm{mM}, K_{1 / 2}\left(\mathrm{~K}^{+}\right)=1.0 \pm 0.16 \mathrm{~mm}$, $K_{1 / 2}\left(\mathrm{Cs}^{+}\right)=11.7 \pm 1.37 \mathrm{~mm}$, and $K_{1 / 2}\left(\mathrm{Li}^{+}\right)=34.8 \pm 4.5 \mathrm{~mm}$.

formed with $\mathrm{RbCl}, \mathrm{KCl}$, and $\mathrm{LiCl}$. Figure $2 B$ shows that the binding affinities follow the order of $\mathrm{Rb}^{+} \simeq \mathrm{K}^{+}>\mathrm{Cs}^{+}$ $>\mathrm{Li}^{+}$. The average half-saturating concentrations determined from sets of 3 experiments for each ion species were $K_{1 / 2}\left(\mathrm{Rb}^{+}\right)=0.8 \pm 0.05 \mathrm{mM}, K_{1 / 2}\left(\mathrm{~K}^{+}\right)=0.9 \pm 0.08$ $\mathrm{mM}, K_{1 / 2}\left(\mathrm{Cs}^{+}\right)=12.0 \pm 1.37 \mathrm{mM}$, and $K_{1 / 2}\left(\mathrm{Li}^{+}\right)=32.0$ $\pm 2.9 \mathrm{mM}$.

\section{Binding of Divalent Cations and Their ANTAGONISTIC EFFECTS with ReSPECT TO $\mathrm{Na}^{+}$}

When experiments with divalent cations were performed, similar to that with $\mathrm{Na}^{+}$shown in Fig. 1, a complex behavior of the RH421 fluorescence was found upon addition of $\mathrm{MgCl}_{2}, \mathrm{CaCl}_{2}, \mathrm{SrCl}_{2}$, and $\mathrm{BaCl}_{2}$ up to 100 $\mathrm{mm}$. Control experiments proved that part of the effect was caused by an unspecific interaction of the divalent 
cations with the membrane fragments. As such controls membrane fragments were incubated at $58^{\circ} \mathrm{C}$ for one $\mathrm{hr}$, after this period no enzymatic activity and no electrogenic $\mathrm{Na}^{+}$binding could be detected. With this inactivated enzyme and also with ouabain-inhibited ion pumps the titration experiments with divalent cations were repeated and a small fluorescence increase $(<3 \%)$ was found at low concentrations. At higher concentrations the unspecific effect was an almost linear fluorescence decrease of about $8 \%$ when the concentration of the divalent ions was increased up to $100 \mathrm{~mm}$. A similar concentration-dependent fluorescence behavior was found also when vesicle preparations, which consisted of phospholipids without protein, were used instead of membranes containing inactivated Na,K-ATPase. From titration experiments with native and denatured membrane preparations the unspecific fluorescence changes were determined under otherwise identical conditions and subtracted from the fluorescence changes of the untreated membranes at the same ion concentrations. The difference was plotted as Na,K-ATPase-specific signals (Fig. $3 A$ ). While $\mathrm{Sr}^{2+}$ and $\mathrm{Ba}^{2+}$ cause a fluorescence decrease in the order of $15 \%$ at a concentration of $100 \mathrm{~mm}$, a biphasic behavior was found in the case of $\mathrm{Mg}^{2+}$ and $\mathrm{Ca}^{2+}$. It seemed that in the case of the $\mathrm{Ca}^{2+}$ titration both effects, increase and decrease, almost canceled out each other. A significant initial increase was found only for $\mathrm{Mg}^{2+}$ ions. The $\mathrm{Ca}^{2+}$-induced effect, $\Delta F_{\max } / F_{0}$, was $\leq 3 \%$ and cannot be regarded as significant. The decaying part of the fluorescence intensity could be fitted with a simple binding isotherm with a $K_{M}$ of $15 \mathrm{~mm}$ for all four ion species. The highly specific effect observed with $\mathrm{Mg}^{2+}$ can be fitted with a sum of two binding isotherms with $K_{M, 1}=0.5 \mathrm{~mm}$ and $K_{M, 2}=15 \mathrm{~mm}$.

The effect of the presence of $10 \mathrm{~mm}$ divalent cations in the buffer on $\mathrm{Na}^{+}$binding is shown in Fig. 3B. A $\mathrm{Na}^{+}$-titration experiment in the absence of divalent ions is shown for comparison (dashed line). Figure $3 B$ shows that the presence of $10 \mathrm{~mm} \mathrm{Mg}{ }^{2+}$ or $\mathrm{Ca}^{2+}$ induced a significant reduction of the apparent $\mathrm{Na}^{+}$-binding affinity from $K_{M}=0.6$ to $9.8 \mathrm{mM}\left(\mathrm{Mg}^{2+}\right)$ and $47 \mathrm{mM}\left(\mathrm{Ca}^{2+}\right)$, while the Hill coefficient, $n_{\mathrm{H}}=1.7$, obtained from the fits to the data was increased when compared to $n_{\mathrm{H}}=$ 1.46 in the absence of divalent cations. The presence of $\mathrm{Sr}^{2+}$ and $\mathrm{Ba}^{2+}$ affected not only the half-saturating $\mathrm{Na}^{+}$ concentration which increased to $2.44 \mathrm{~mm}\left(\mathrm{Ba}^{2+}\right)$ and 12 $\mathrm{mm}\left(\mathrm{Sr}^{2+}\right)$, but reduced the Hill coefficient to 0.7 for both ions. The decrease of the Hill coefficient from 1.7 to a value below 1 indicates a significantly altered cooperativity in the $\mathrm{Na}^{+}$binding process.

The observed antagonistic effect of $\mathrm{Mg}^{2+}$ and $\mathrm{Na}^{+}$ ions is of potential physiological importance, and was therefore investigated in detail. The concentration of the other divalent cations in the cytoplasm may be neglected under physiological conditions. In Fig. $4 A$ it is demon-
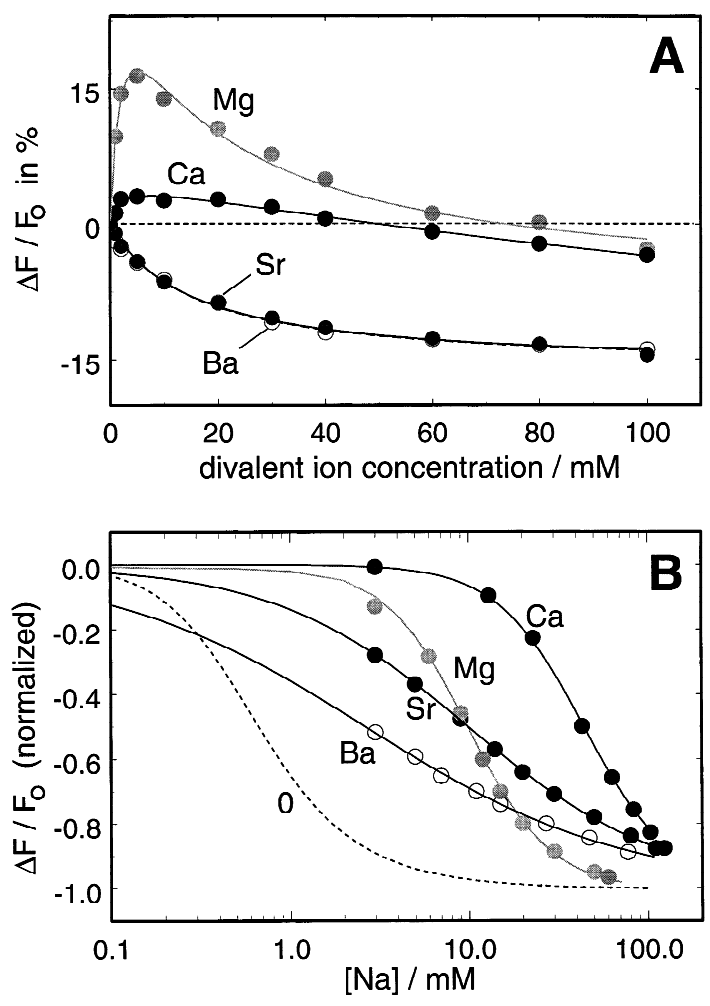

Fig. 3. Binding of divalent cations to the Na,K-ATPase detected by changes of the RH421 fluorescence intensity. (A) Effect of binding of $\mathrm{Mg}^{2+}, \mathrm{Ca}^{2+}, \mathrm{Sr}^{2+}$, and $\mathrm{Ba}^{2+}$ in state $\mathrm{E}_{1}$ on $\mathrm{RH} 421$ fluorescence in the absence of other cations. Common to all four ion species was a low affinity effect with a half-saturating concentration of $\sim 15 \mathrm{~mm}$ that was represented by a relative decrease in the order of $15 \%$ at $100 \mathrm{~mm}$. In the case of $\mathrm{Ca}^{2+}$ this decrease was mostly compensated by an almost corresponding increase with higher affinity, in the case of $\mathrm{Mg}^{2+}$ a dominating increase with a half-saturating $\mathrm{Mg}^{2+}$ concentration of $\sim 0.5 \mathrm{mM}$ could be detected. $(B)$ The antagonistic effect of the divalent cations on $\mathrm{Na}^{+}$binding is demonstrated by $\mathrm{Na}^{+}$titration experiments in the absence $(0)$ and presence of $10 \mathrm{~mm}$ of the indicated divalent ions. All divalent cations led to a shift of the fluorescence decrease which corresponds to a decrease of the apparent binding affinity for $\mathrm{Na}^{+}$. In addition $\mathrm{Sr}^{2+}$ and $\mathrm{Ba}^{2+}$ altered the binding kinetics for $\mathrm{Na}^{+}$significantly (Hill coefficient $n_{\mathrm{H}}<1$ ) as can be seen from the less steep concentration dependence.

strated that in state $\mathrm{E}_{1}$ the high (apparent) $\mathrm{Na}^{+}$affinity of the ion-binding sites with a $K^{\mathrm{Na}}$ of about $0.67 \pm 0.02 \mathrm{~mm}$ in the absence of $\mathrm{Mg}^{2+}$ can be apparently reduced to $K^{\mathrm{Na}}$ $=8.7 \pm 0.4 \mathrm{~mm}$ by addition of $10 \mathrm{mM} \mathrm{MgCl}_{2}$ during the course of the titration experiment. In the data shown the $\mathrm{Mg}^{2+}$ concentration was raised in the presence of $3 \mathrm{~mm}$ $\mathrm{Na}^{+}$. The same experiments were performed with varying $\mathrm{Na}^{+}$concentrations at which $\mathrm{Mg}^{2+}$ was added (not shown). The resulting "low-affinity" $\mathrm{Na}^{+}$binding curves coincided for all experiments (corresponding to the upper solid line in Fig. 4A). The same transition from high to apparent low affinity could also be observed when $\mathrm{Ca}^{2+}, \mathrm{Sr}^{2+}$, or $\mathrm{Ba}^{2+}$ was added instead of $\mathrm{Mg}^{2+}$; (data not shown.) In Fig. $4 B$ the RH421 fluorescence increase 

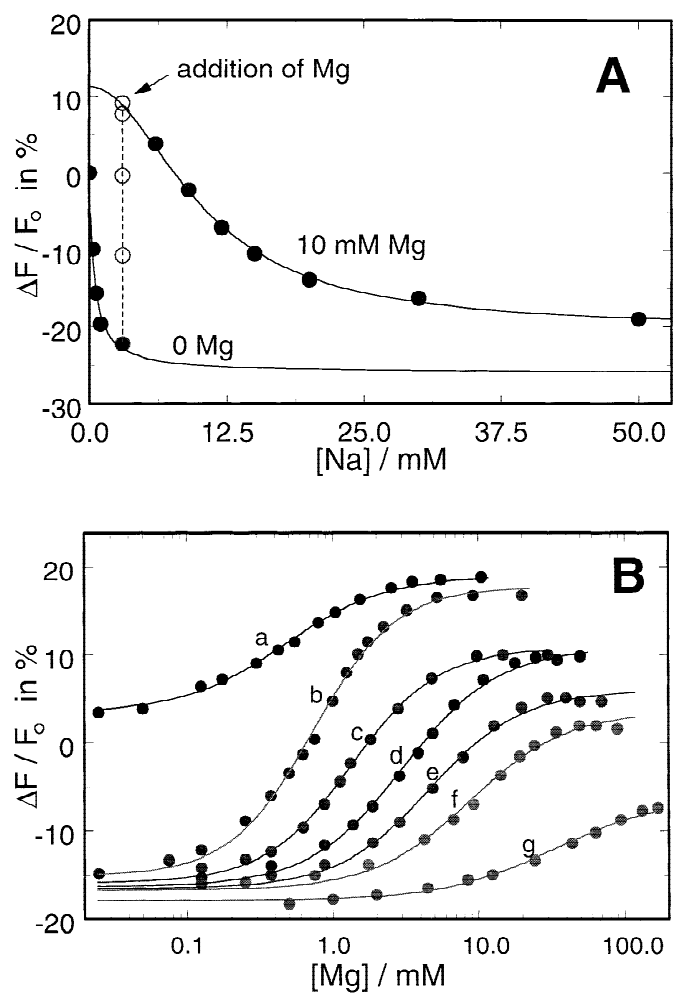

Fig. 4. $\mathrm{Na}^{+} / \mathrm{Mg}^{2+}$ antagonism at the ion binding sites in state $\mathrm{E}_{1}$ as detected by RH421. The fluorescence changes were calculated with respect to the fluorescence intensity prior the addition of any cations. (A) Transition from high-affinity $\mathrm{Na}^{+}$binding to low-affinity binding by subsequent addition of $10 \mathrm{mM} \mathrm{Mg}^{2+}$. The half-saturating $\mathrm{Na}^{+}$concentration increases from $0.6 \mathrm{~mm}$ to about $9.2 \mathrm{~mm}$. (B) Correspondingly it could be shown that the $\mathrm{Mg}^{2+}$ ions induced reversal of the $\mathrm{Na}^{+}$effect on the RH421 fluorescence. Increasing concentrations of $\mathrm{Na}^{+}, 0$ (a), 2.5 $\mathrm{mm}$ (b), $5 \mathrm{~mm}$ (c), $7.5 \mathrm{~mm}$ (d), 10 (e), $15 \mathrm{~mm}$ (f), $50 \mathrm{~mm}$ (g) required higher $\mathrm{Mg}^{2+}$ concentrations to produce the fluorescence increase that reflects the removal of the electrogenically bound $\mathrm{Na}^{+}$ion from its (specific) binding site. All sets of data may be fitted by a Hill function (Eq. 1) with the same Hill coefficient of $n_{\mathrm{H}}=1.33$.

upon $\mathrm{Mg}^{2+}$ addition in the presence of various $\mathrm{Na}^{+}$concentrations between 0 and $50 \mathrm{~mm}$ is plotted as function of the $\mathrm{Mg}^{2+}$ concentration. Trace e in Fig. $4 B$ corresponds to the course of the $\mathrm{Mg}^{2+}$ additions in Fig. $4 A$ as indicated there by the dashed line. Trace a shows in an expanded presentation the rising phase of fluorescence signal for the $\mathrm{Mg}^{2+}$ trace in Fig. 3A. All $\mathrm{Mg}^{2+}$-titration experiments could be fitted reasonably with a Hill coefficient of 1.33. When the Hill coefficient was varied by the fitting procedure optimal fits were found with similar half-saturating $\mathrm{Mg}^{2+}$ concentrations, $K^{\mathrm{Mg}}$, however, the Hill coefficients varied between 1 and 1.5. The shift of $K^{\mathrm{Mg}}$ to higher values with increasing $\mathrm{Na}^{+}$concentration indicates that $\mathrm{Mg}^{2+}$ binds to a site which is affected by $\mathrm{Na}^{+}$in a competitive manner. The dependence of $K^{\mathrm{Mg}}$ on the $\mathrm{Na}^{+}$concentration is shown in Fig. 5A. The data presented are the average of three measurements, at most
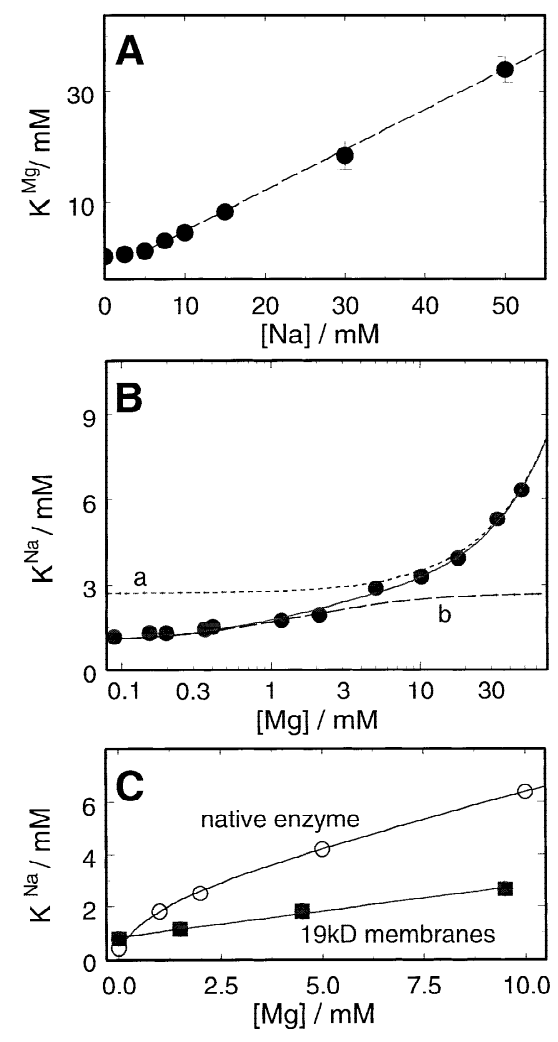

Fig. 5. Comparison of the mutual displacement of $\mathrm{Na}^{+}$and $\mathrm{Mg}^{2+}$ from their binding site(s) in the $\mathrm{E}_{1}$ state of the $\mathrm{Na}, \mathrm{K}$-ATPase. (A) Halfsaturating $\mathrm{Mg}^{2+}$ concentration, $K^{\mathrm{Mg}}$, as a function of the $\mathrm{Na}^{+}$concentration present in the buffer. The values of $K^{\mathrm{Mg}}$ above $5 \mathrm{mM} \mathrm{Na}^{+}$can be fitted by a regression line (dashed line) as expected from competitive binding. (B) Half-saturating $\mathrm{Na}^{+}$concentrations, $K^{\mathrm{Na}}$, as a function of the $\mathrm{Mg}^{2+}$ concentration in the buffer. The complex dependence on the $\mathrm{Mg}^{2+}$ concentration can be described by two independent processes, a competitive binding with low affinity (line a) and a noncompetitive (and saturating) binding with high affinity (line b). The total effect of both mechanisms fitted the data satisfactorily (solid line). (C) Comparison of the half-saturating $\mathrm{Na}^{+}$concentration, $K^{\mathrm{Na}}$, obtained from native enzyme and $19 \mathrm{kD}$ membranes. In contrast to the native enzyme, the trypsinized ion pumps show no saturating component of $\mathrm{Mg}^{2+}$ binding, the straight line is an indication of a competitive process between $\mathrm{Na}^{+}$and $\mathrm{Mg}^{2+}$. Both series of experiments were performed with protein from the same preparation.

$\mathrm{Na}^{+}$concentrations the standard error of the mean is smaller than the size of the data point. Below a $\mathrm{Na}^{+}$ concentration of $5 \mathrm{~mm}$ the value of $K^{\mathrm{Mg}}$ was not significantly affected, above $5 \mathrm{~mm}$ the half-saturating $\mathrm{Mg}^{2+}$ concentration increased linearly with the $\mathrm{Na}^{+}$concentration. The latter behavior may be described by the mechanism of competitive binding of both cations,

$K(\mathrm{Mg}) \equiv K^{\mathrm{Mg}}([\mathrm{Na}])=K^{\mathrm{Mg}}(0 \mathrm{Na}) \times\left(1+\frac{[\mathrm{Na}]}{K^{\mathrm{Na}}}\right)$

With the value of $K^{\mathrm{Mg}}(0 \mathrm{Na})=0.5 \mathrm{~mm}$ and the slope of 
the regression line in Fig. $5 A$ an apparent $K^{\mathrm{Na}}$ was determined to be $0.4 \mathrm{~mm}$ which is consistently close to the experimentally obtained (apparent) value of $0.67 \mathrm{~mm}$ (Fig. 1).

When present in the buffer (and therefore, also in or close to the ion binding sites) the effect of $\mathrm{Mg}^{2+}$ on the half-saturating $\mathrm{Na}^{+}$concentration, $K^{\mathrm{Na}}$, is more complex (Fig. $5 B$ ). The simplest mechanism which fitted $K^{\mathrm{Na}}$ as function of the $\mathrm{Mg}^{2+}$ concentration was obtained by the assumption of two processes, a noncompetitive inhibition by $\mathrm{Mg}^{2+}$ with an affinity of $\sim 1.5 \mathrm{~mm}$ (trace b), and a competitive inhibition which controlled the halfsaturating $\mathrm{Na}^{+}$concentration above $5 \mathrm{mM} \mathrm{Mg}^{2+}$ (trace a). With an equation corresponding to Eq. (2) an apparent $K^{\mathrm{Mg}}$ of $\sim 2 \mathrm{~mm}$ was determined (with $K^{\mathrm{Na}}(0 \mathrm{Mg})=0.5$ $\mathrm{mM})$. The competitive process is proposed to occur at/or in proximity to the ion-binding sites. To get additional information on the mechanism of the noncompetitive process complementary experiments were performed in which $\mathrm{Na}^{+}$-binding was studied with $19 \mathrm{kDa}$ membranes in the absence and presence of various $\mathrm{Mg}^{2+}$ concentrations (Fig. 5C). In the case of the truncated $\mathrm{Na}, \mathrm{K}$ ATPase in which most of its cytoplasmic part was removed, and the enzymatic machinery of the protein was missing, only the competitive process between $\mathrm{Na}^{+}$and $\mathrm{Mg}^{2+}$ was observed. It is known from recent experiments [35] that in the $19 \mathrm{kDa}$ preparation the binding sites are accessible from the cytoplasmic side, however, the $\mathrm{Na}^{+}$affinity is slightly reduced $\left(K^{\mathrm{Na}}=0.83 \mathrm{~mm}\right.$ in the absence of $\left.\mathrm{Mg}^{2+}\right)$. Therefore, it may be expected that also the (apparent) half-saturating $\mathrm{Mg}^{2+}$ concentration obtained in these competition experiments is altered. From the data shown in Fig. $5 C$ for the $19 \mathrm{kDa}$ membranes a $K^{\mathrm{Mg}}$ of $\sim 4.3 \mathrm{~mm}$ was calculated. The disappearance of the noncompetitive process indicates that it has to be related to the removed parts of the protein. An obvious site could be the nucleotide binding site, since it is well known that ATP interacts with the ion pump as a $\mathrm{Mg} \cdot \mathrm{ATP}$ complex, and that $\mathrm{Mg}^{2+}$ is bound during backdoor phosphorylation by inorganic phosphate [29].

To obtain additional information on the nature of the $\mathrm{Mg}^{2+}$-binding moiety, $\mathrm{Mg}^{2+}$ titration experiments were performed in the absence of $\mathrm{Na}^{+}$at various $\mathrm{pH}$ values of the buffer. The buffer used in these experiments consisted of $25 \mathrm{~mm}$ histidine and $20 \mathrm{~mm}$ TRIS, the $\mathrm{pH}$ was adjusted by addition of $\mathrm{HCl}$. The $\mathrm{Mg}^{2+}$-induced fluorescence increase (as shown in Fig. 4B) was measured in the $\mathrm{pH}$ range between 5.8 and 8 . The titration curves at each $\mathrm{pH}$ were fitted by the Hill function (Eq. 1) and halfsaturating $\mathrm{Mg}^{2+}$ concentrations, $K^{\mathrm{Mg}}$, were obtained as plotted in Fig. 6. The Hill coefficient of the $\mathrm{Mg}^{2+}$ binding curves were $\sim 1$ throughout. The $\mathrm{pH}$ dependence of $K^{\mathrm{Mg}}$ could be reproduced by the Henderson-Hasselbalch equation,

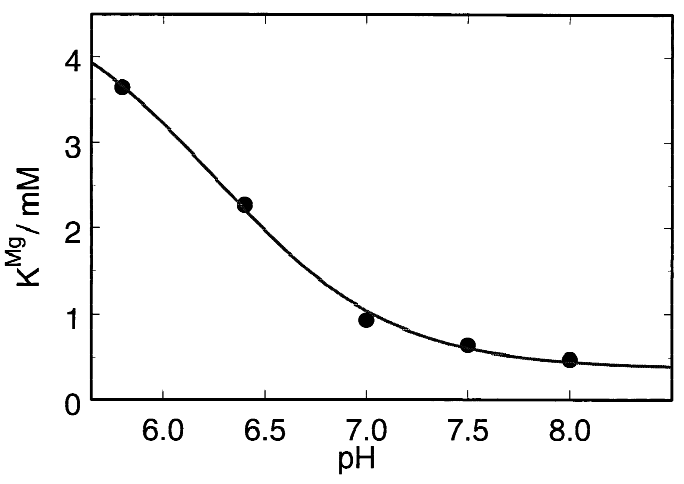

Fig. 6. $\mathrm{pH}$ dependence of $\mathrm{Mg}^{2+}$ binding to its binding moiety on the cytoplasmic side of the $\mathrm{Na}, \mathrm{K}-\mathrm{ATPase}$. From $\mathrm{Mg}^{2+}$ titrations at specific $\mathrm{pH}$ values of the buffer the half-saturating concentrations, $K^{\mathrm{Mg}}$, were obtained by fits with Michaelis-Menten functions, $\Delta F([\mathrm{Mg}]) / F_{0}=$ $\Delta F(\infty) \cdot[\mathrm{Mg}] /\left(K^{\mathrm{Mg}}+[\mathrm{Mg}]\right)$, and plotted as a function of the buffer $\mathrm{pH}$. The line is a fit to the data points according to the HendersonHasselbalch equation (Eq. 3). The pK of the curve was determined to be 6.25 .

$\mathrm{pH}=\mathrm{pK}+\log \frac{\alpha}{1-\alpha}$,

where $\alpha$ is the dissociation ratio of an acidic group which is involved in $\mathrm{Mg}^{2+}$ binding and which can be titrated in the $\mathrm{pH}$ range covered by the experiments. The fit to the data shown is in agreement with the assumption that $\mathrm{Mg}^{2+}$ binding is $\mathrm{pH}$ dependent and is affected by a negatively charged side chain of an amino acid, which recombines with a proton at low pH. From Fig. 6 the apparent $\mathrm{pK}$ of this group was determined to be 6.25 .

BindiNG OF TRIVALENT $\mathrm{Br}_{2}-\mathrm{TITU}^{3+}$ AND ITS Antagonistic EfFects with Respect to $\mathrm{Na}^{+}$

As has been demonstrated a couple of years ago, the large trivalent organic cation $\mathrm{Br}_{2}-\mathrm{Titu}^{3+}$ binds to the $\mathrm{Na}, \mathrm{K}$-ATPase in the $\mathrm{E}_{1}$ conformation and affects $\mathrm{Na}^{+}$ binding [18]. To investigate the underlying mechanism in detail $\mathrm{Na}^{+}$titration experiments were performed in the presence of $\mu$ molar concentrations of $\mathrm{Br}_{2}-\mathrm{Titu}^{3+}$, from which half-saturating concentrations of $\mathrm{Na}^{+}$binding were determined as detected by RH421 experiments. It was found that the $\mathrm{Na}^{+}$binding affinity was decreased with increasing $\mathrm{Br}_{2}-\mathrm{Titu}^{3+}$ (Fig. 7). The half-saturating $\mathrm{Na}^{+}$concentrations, $K^{\mathrm{Na}}$, could be modeled satisfactorily according to the reaction mechanism shown in Fig. $7 B$, but not with a scheme including a state with mixed binding of $\mathrm{Na}^{+}$and $\mathrm{Br}_{2}-\mathrm{Titu}^{3+}$. With the constants of $\mathrm{Na}^{+}$ binding as given in Fig. 1 the equilibrium dissociation constant for $\mathrm{Br}_{2}-\mathrm{Titu}^{3+}$ was calculated to be $6.4 \mathrm{nM}$. The curved shape of the fitting curve, unexpected for competitive binding, is caused by the fact that three $\mathrm{Na}^{+}$ions bind in contrast to the single competitor ion. For very 

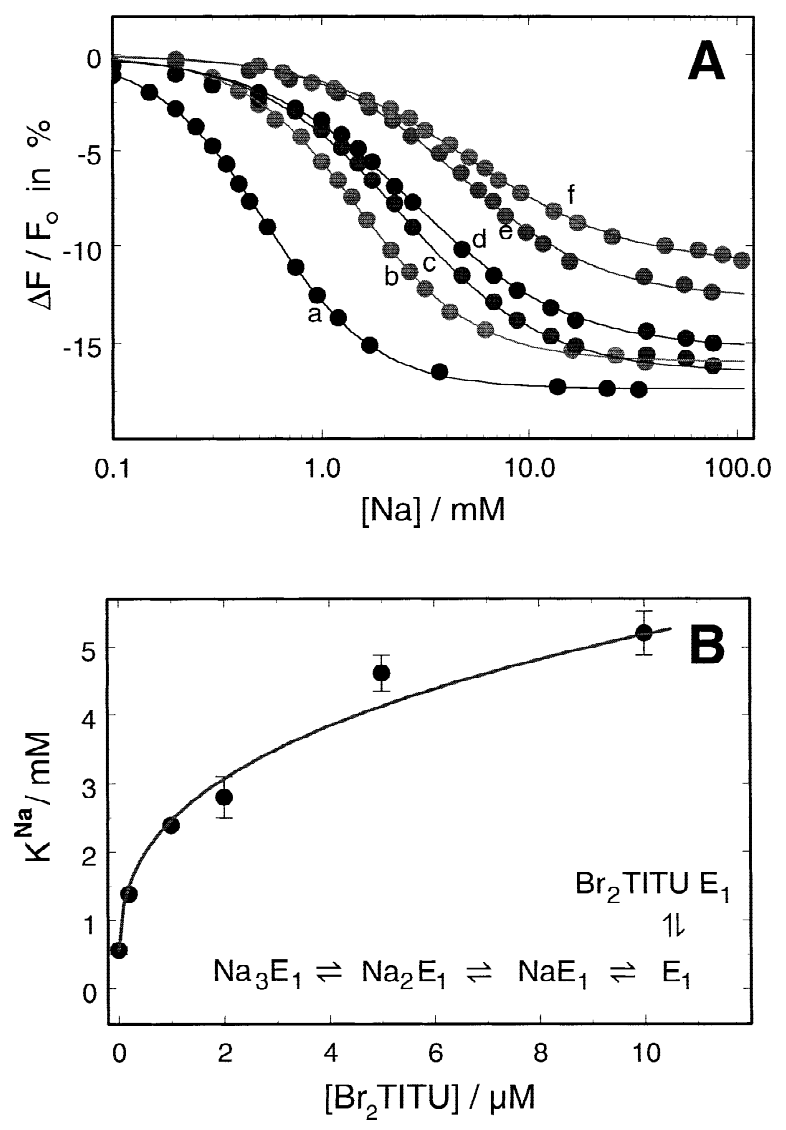

Fig. 7. Effect of the trivalent organic cation $\mathrm{Br}_{2}-\mathrm{Titu}^{3+}$ on the $\mathrm{Na}^{+}$ binding to the Na,K-ATPase. (A) Titration of the cytoplasmic binding sites with $\mathrm{Na}^{+}$in the absence (a) and presence of various concentrations of the competitor $\mathrm{Br}_{2}-\mathrm{Titu}^{3+}$ (b: $0.2 \mu \mathrm{M}, \mathrm{c}: 1 \mu \mathrm{M}, \mathrm{d}: 2 \mu \mathrm{M}$, e: $5 \mu \mathrm{M}$, f: $10 \mu \mathrm{M})$. To determine the half-saturating $\mathrm{Na}^{+}$concentrations, $K^{\mathrm{Na}}$, the experiments were fitted with Hill functions (Eq. 1). The maximum fluorescence changes were $\Delta F_{\max }=15.8 \pm 1.8$, the Hill coefficients $n_{\mathrm{H}}$ $=1.34 \pm 0.2$. $(B)$ The values of $K^{\mathrm{Na}}$ were plotted against the concentration of $\mathrm{Br}_{2}-\mathrm{Titu}^{3+}$ and fitted by the analytically determined function of $K^{\mathrm{Na}}$ from the reaction scheme shown as inset. The only free parameter was the equilibrium dissociation constant of $\mathrm{Br}_{2}-\mathrm{Titu}^{3+}$ since those of $\mathrm{Na}^{+}$binding were set as obtained independently (Fig. 1).

high concentrations of the competitor the calculated value of $K^{\mathrm{Na}}$ increase linearly with $\left[\mathrm{Br}_{2}-\mathrm{Titu}^{3+}\right]$, as it is expected from competitive binding (not shown).

\section{Discussion}

The data presented in this paper are all related to the interaction of cations with the cytoplasmic ion-binding sites of the Na,K-ATPase. They allow, together with other recent findings, an extensive characterization of the properties of these sites and the formulation of constraints on structure-function relations for the sodium pump.

\section{Binding OF $\mathrm{Na}^{+}$IN THE AbSENCE OF Other CATIONS}

In the sequence of ion binding and release steps of monovalent cations in the $\mathrm{E}_{1}$ conformation of the $\mathrm{Na}, \mathrm{K}$ ATPase only a single step can be detected directly by the methods known so far, which is binding of the third $\mathrm{Na}^{+}$ ion, $\mathrm{Na}_{2} \mathrm{E}_{1} \rightleftharpoons \mathrm{Na}_{3} \mathrm{E}_{1}$. This reaction can be monitored by fluorescent probes such as RH421 and FITC [30] or by direct electric measurements of changes of the membrane capacitance, and it has been shown that all three methods detect identical behavior of the protein as a function of the $\mathrm{Na}^{+}$concentration [12]. Since the experiments with RH421 as well as the changes of the membrane capacitance are related to electrogenic processes, it could be proven that binding of the third $\mathrm{Na}^{+}$ion is the only electrogenic event on the cytoplasmic side of the $\mathrm{Na}, \mathrm{K}-\mathrm{ATPase}$. The observation that exclusively $\mathrm{Na}^{+}$is able to bind as a third ion indicates that this site is extremely selective for $\mathrm{Na}^{+}$; no other ions have been found to introduce a positive charge into the protein dielectric. From recent studies is was shown that the $\mathrm{Na}^{+}$ion has to cross about $25 \%$ of membrane dielectric (or membrane potential) to reach its site $[12,25]$.

The special role of the third $\mathrm{Na}^{+}$-binding site can be seen also from the titrations with $\mathrm{Na}^{+}$only. The concentration dependence of the RH421 fluorescence as shown in Fig. 1 revealed that under the assumption of sequential binding of three $\mathrm{Na}^{+}$ions a fit of the data always led to the result that the equilibrium dissociation constant of the third $\mathrm{Na}^{+}$was smaller than that of the second (or: that the affinity of the third site for $\mathrm{Na}^{+}$was higher than for the second). This may occur only in the case that the third site becomes available after the first two sites are occupied, otherwise the third site would be filled before the second.

This observation has implications on the mechanism of ion binding which may be proposed on the basis of either of two models published for the SR-Ca-ATPase. In the first model Tanford et al. proposed a so-called jaw-closing model [36] in which by a single-file mechanism the second $\mathrm{Ca}^{2+}$ binding site is formed "on top" of the first by a structural change of the entrance funnel of the protein. The second, more recent proposal dispenses with the single file mechanism and proposes two sites which are positioned in the protein abreast [24]. Menguy and collaborators suggested that the cytoplasmic loop located between transmembrane segments 6 and 7, L6/7, controls the access to the first and second $\mathrm{Ca}^{2+}$ binding site, and that this process could be related with the occlusion of the first $\mathrm{Ca}^{2+}$ by a movement of the L6/7 over the first site, thus opening the second [24]. The recent publication of the crystal structure of the SR Ca-ATPase has proven the side by side binding of $\mathrm{Ca}^{2+}$ ions, although the loop L6/7 has been given a different assignment as to how it affects $\mathrm{Ca}^{2+}$ binding [37]. Due to the 
fact that the structure of the SR-Ca-ATPase and the $\mathrm{Na}, \mathrm{K}-\mathrm{ATPase}$ are closely related $[38,39]$ an analogous conclusion may be drawn on the basis of the recent proposal, especially since it was found that in the case of the $\mathrm{Na}, \mathrm{K}$-ATPase the L6/7 is of similar importance for the interaction of cations with the cytoplasmic ion sites [35]. The side-by-side model would imply that the third, $\mathrm{Na}^{+}-$ specific binding site becomes accessible by a movement of L6/7 only after two $\mathrm{Na}^{+}$ions are already bound and "pre-occluded" [31].

\section{Competition Between Monovalent Cations}

In the absence of a detectable signal specific to binding of $\mathrm{K}^{+}$(or its congeners $\mathrm{Li}^{+}, \mathrm{Rb}^{+}, \mathrm{Cs}^{+}$) this process can be studied only in competition with $\mathrm{Na}^{+}$, or by the subsequent conformational transition, $\mathrm{K}_{2} \mathrm{E}_{2} \rightleftharpoons \mathrm{E}_{2}\left(\mathrm{~K}_{2}\right)$, if the enzyme was labeled with FITC $[21,30]$. It was found that all these ions (and in addition $\mathrm{NH}_{4}^{+}$and $\mathrm{Tl}^{+}$, not shown) are able to displace (at least the electrogenically bound) $\mathrm{Na}^{+}$from its site(s) (Fig. 2). Obviously the mechanism is not caused by a direct interaction of ions but by a shift of the steady-state population to the left side in the following reaction scheme,

$\mathrm{E}_{2}\left(\mathrm{~K}_{2}\right) \rightleftharpoons \mathrm{K}_{2} \mathrm{E}_{1} \rightleftharpoons \mathrm{KE}_{1} \rightleftharpoons \mathrm{E}_{1} \rightleftharpoons \mathrm{NaE}_{1} \rightleftharpoons \mathrm{Na}_{2} \mathrm{E}_{1} \rightleftharpoons$ $\mathrm{Na}_{3} \mathrm{E}_{1}$,

which is possible under the reasonable assumption that forward and backward reaction steps occur with rate constants which are high compared to the time of the experimental resolution. In the absence of $\mathrm{Mg} \cdot \mathrm{ATP}$ and inorganic phosphate the pump is confined to the reaction sequence shown in the scheme above.

According to the varying affinities of $\mathrm{K}^{+}$and its congeners different concentrations were needed to reverse $\mathrm{Na}^{+}$binding. The half-saturating concentrations of the ions competing with $\mathrm{Na}^{+}$may be plotted against the radius of the respective dehydrated ions (Fig. 8). To include into Fig. 8 also some information on the binding affinity for $\mathrm{Na}^{+}$we estimated a (relative) effect for $\mathrm{Na}^{+}$ from independently determined half-saturating concentrations for $\mathrm{Na}^{+}$and $\mathrm{K}^{+}$in the absence of all other cations as they were obtained from experiments with FITClabeled Na,K-ATPase [30], in which the ratio of $K_{1 / 2}$ Na/ $K_{1 / 2}{ }^{\mathrm{K}}$ was 4.2 . From the dependence of the $K_{1 / 2}$ values it can be seen that (dehydrated) ions with a radius of about $1.4 \AA$ were bound strongest to the ion site. Smaller cations, such as $\mathrm{Na}^{+}$and $\mathrm{Li}^{+}$, may easily enter the site, however, their coordination with the elements of the protein was significantly less stable. The larger cation $\mathrm{Cs}^{+}$ apparently had to deform the binding site to fit into the pocket so that the higher energy needed for this process reduced the binding affinity by more than an order of magnitude when compared with $\mathrm{K}^{+}$or $\mathrm{Rb}^{+}$. The results summarized in Fig. 8 indicate that the structure ion bind-

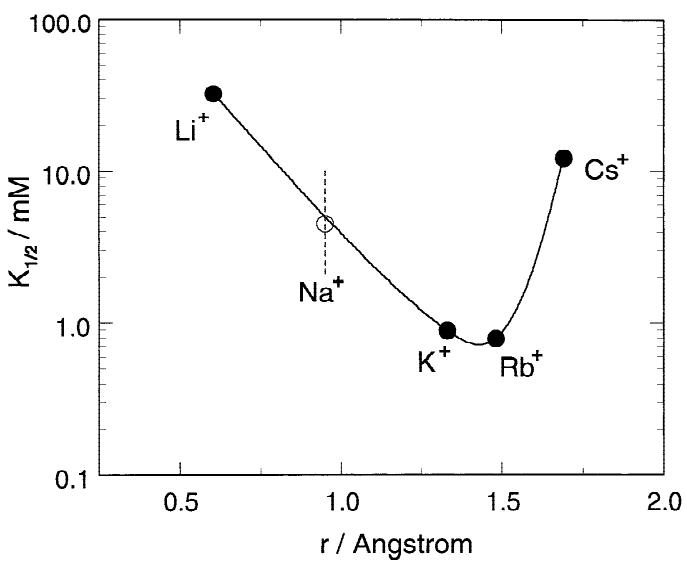

Fig. 8. Competition between monovalent cations at the cytoplasmic binding sites. The half-saturating concentrations, $K_{1 / 2}$, of the alkali ions were determined in the presence of $3 \mathrm{mM} \mathrm{Na}^{+}$(Fig. 2B) and plotted against the radius of the dehydrated ions. The solid line was drawn to guide the eye. The vertical dashed line indicates the radius of the $\mathrm{Na}^{+}$ ion, the open circle represents an estimated value for $\mathrm{Na}^{+}$binding from the ratio of half-saturating concentrations for $\mathrm{Na}^{+}$and $\mathrm{K}^{+}$binding in the absence of other ions [28].

ing sites has to be rather rigid to produce the observed tenfold changes in binding affinity when the radius of the ion differed by $+0.2 \AA$ or $-0.5 \AA$.

\section{EfFects of Divalent Cations}

It was observed that addition of divalent cations in the absence of $\mathrm{Na}^{+}$and $\mathrm{K}^{+}$produced changes of the $\mathrm{RH} 421$ fluorescence intensity. Part of the observed effect was an unspecific interaction of the ions with the lipid membrane, however, even when this contribution was subtracted significant changes were detected (Fig. 3). The physiologically relevant $\mathrm{Mg}^{2+}$ ion produced a biphasic fluorescence response as a function of its concentration in the buffer while $\mathrm{Ca}^{2+}$ had no significant effect $\left(\left|\Delta F / F_{0}\right|\right.$ $\leq 3 \%$ ), and $\mathrm{Sr}^{2+}$ and $\mathrm{Ba}^{2+}$ produced a significant fluorescence decrease at concentrations higher than $10 \mathrm{~mm}$, which were probably correlated with an (irreversible) inactivation of the ion pump. Because of the large radii of $\mathrm{Sr}^{2+}$ and $\mathrm{Ba}^{2+}(1.34 \AA$ and $1.49 \AA$, respectively) and their two positive charges it may be excluded that they produced the decrease of $\mathrm{RH}$ fluorescence by binding electrogenically to the $\mathrm{Na}^{+}$-specific site within the protein dielectric. Therefore, we assume that the Na,KATPase is affected in an unspecific way by high concentrations of the divalent cations. The interaction may occur directly or on the lipid molecules of the surrounding membrane; such interactions are known to inhibit the ion pump [13].

The biphasic fluorescence change which depends on the $\mathrm{Mg}^{2+}$ concentration has a rising phase with a $K^{\mathrm{Mg}} \sim$ $0.5 \mathrm{mM}$, which is comparable to the concentrations that are characteristic for $\mathrm{Mg}^{2+}$ binding to both, the competi- 
tive and noncompetitive sites (Fig. 5). According to the electrochromic mechanism an increase of the RH421 fluorescence represents a less positive electric potential in the protein/membrane dielectric when $\mathrm{Mg}^{2+}$ is bound. Comparable effects were found also in the case of 19 $\mathrm{kDa}$ membranes. This process is not understood so far. For example it could be induced by a rearrangement of carboxylic side chains of amino acids or the dipoles of the transmembrane $\alpha$ helices (detailed investigations are planned). The decreasing phase of the concentration dependent fluorescence change at high concentrations is comparable to the $\mathrm{Sr}^{2+}$ or $\mathrm{Ba}^{2+}$ induced effect.

Figure $3 B$ shows that the divalent cations affect $\mathrm{Na}^{+}$ binding. $\mathrm{Mg}^{2+}$ and $\mathrm{Ca}^{2+}$ mainly shift the half-saturating $\mathrm{Na}^{+}$concentrations to higher values, the Hill coefficient is not strongly increased. It is obvious that $\mathrm{Ca}^{2+}$ is more tightly bound than $\mathrm{Mg}^{2+}$ since a fivefold higher $\mathrm{Na}^{+}$ concentration is needed to get the third $\mathrm{Na}^{+}$ion bound in the presence of $10 \mathrm{~mm}$ of the divalent cation. The cytoplasmic loop L6/7 was recently proposed as a possible candidate for the site to which the divalent cations could bind [35]. This observation is in agreement with corresponding findings for the Ca-ATPase [24].

Remarkable in Fig. $3 B$ is the significantly different concentration dependence in the presence of $10 \mathrm{mM} \mathrm{Sr}^{2+}$ and $\mathrm{Ba}^{2+}$. The data were fitted by the Hill function (Eq. 1) with a Hill coefficient of 0.7 , which is an indication for a negative cooperativity. A possible explanation could be that (in contrast to the findings in the presence of $\mathrm{Mg}^{2+}$ and $\mathrm{Ca}^{2+}$ ) binding of the first $\mathrm{Na}^{+}$ion to its assigned site on the pump significantly destabilizes binding of the (larger) $\mathrm{Ba}^{2+}$ and $\mathrm{Sr}^{2+}$ ions.

Physiologically relevant for the function of the $\mathrm{Na}, \mathrm{K}$-ATPase is mainly $\mathrm{Mg}^{2+}$ since the concentration of other divalent cations is controlled strictly and kept well below $1 \mathrm{~mm}$. Figures $4 A$ and 5 demonstrate that at physiological concentrations of $2 \mathrm{~mm}$ up to $10 \mathrm{mM} \mathrm{Mg}^{2+}$ the interaction of $\mathrm{Na}^{+}$with its binding sites is significantly affected. From the results shown in Fig. 5 it may be derived that $\mathrm{Na}^{+}$and $\mathrm{Mg}^{2+}$ compete for the same site or, if the sites are not identical, that they have to be so close to each other that they sterically overlap and exclude simultaneous occupation by both species.

Due to the fact that $\mathrm{Mg}^{2+}$ binding does not produce a fluorescence decrease at concentrations below $10 \mathrm{~mm}$ in the RH421 experiments it may be excluded that the competition occurs at the third, "Na-specific" site. Initially each of the other two $\mathrm{Na}^{+}$sites which are discriminated by their equilibrium dissociation constants could be proposed to interfere with the $\mathrm{Mg}^{2+}$-binding site. The search for the simplest reaction scheme which convincingly reproduces the titration experiments led to the reaction model shown in Fig. 9A. In this model it is assumed that $\mathrm{Mg}^{2+}$ binds to or affects the site with the lower $\mathrm{Na}^{+}$affinity and that a mixed state is possible in

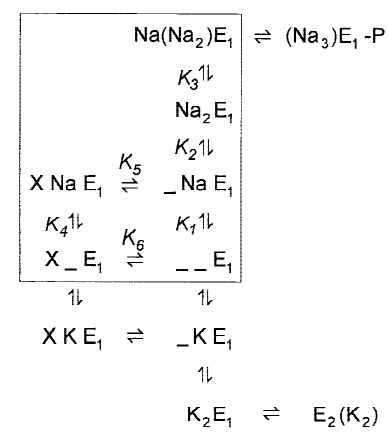

A

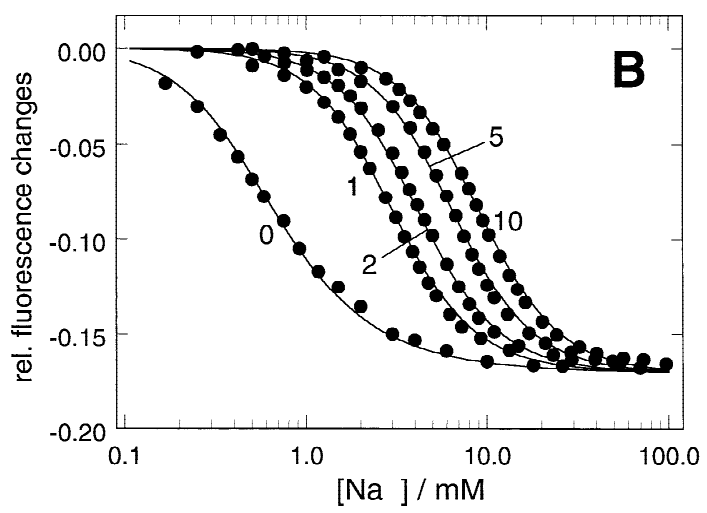

Fig. 9. Schematic representation of the competition of cations for the cytoplasmic binding sites of the Na,K-ATPase. (A) Reaction model for a satisfactory simulation of all experiments presented in this paper. " $X$ " signifies a cation of any valence, e.g., $\mathrm{Mg}^{2+}, \mathrm{Ca}^{2+}, \mathrm{Br}_{2}-\mathrm{Titu}^{3+}$. "." represents an empty and accessible site. The equilibrium dissociation constants, $K_{1}, \ldots, K_{6}$, were used when simulating the $\mathrm{Na}^{+} / \mathrm{Mg}^{2+}$ antagonism. The box denotes the possible reaction steps when only $\mathrm{Na}^{+}$ and $\mathrm{Mg}^{2+}$ were present in the buffer. $(B)$ Inhibition of $\mathrm{Na}^{+}$binding in the presence of various $\mathrm{Mg}^{2+}$ concentrations. The solid lines were calculated according to the framed part of the scheme shown in A. For an explanation of the choice of the equilibrium dissociation constants see Discussion. The numbers connected to the data indicate the $\mathrm{Mg}^{2+}$ concentration (in $\mathrm{mm}$ ) present in these experiments.

which $\mathrm{Na}^{+}$is able to bind to the high-affinity site while the other is still blocked by $\mathrm{Mg}^{2+}$ (or any other cation). An application of this model is shown in Fig. 9B. To fit the fluorescence decrease of the $\mathrm{Mg}^{2+}$-dependent $\mathrm{Na}^{+}$ titration experiments the boxed six-state system in Fig. $9 A$ was used. The equilibrium dissociation constants for $\mathrm{Na}^{+}$binding, $K_{1}, K_{2}, K_{3}$, were taken from the experiment in Fig. 1. In addition it was assumed that $\mathrm{Na}^{+}$or $\mathrm{Mg}^{2+}$ binding to one site would be independent of the presence of another ion at the second site, i.e., $K_{1}=K_{4}$ and $K_{5}=$ $K_{6}$. Under this assumption the $\mathrm{Mg}^{2+}$ effect was accounted for with a single constant for the reaction steps, $\mathrm{E}_{1} \rightleftharpoons \mathrm{MgE}_{1}$ and $\mathrm{NaE}_{1} \rightleftharpoons \mathrm{MgNaE}_{1}, K_{5}=K_{6}=0.031$ mM. This value differs by about an order of magnitude from the experimentally determined $K^{\mathrm{Mg}}=0.5 \mathrm{mM}$, a fact which has to be taken as hint that the assumption, $K_{1}$ $=K_{4}$ and $K_{5}=K_{6}$, may be an oversimplification. In 
addition, we found that numerous (simpler) schemes without the mixed state, $\mathrm{MgNaE}_{1}$, were unable to reproduce the varying shapes of the titration curves in Fig. $9 B$ (not shown). The $\mathrm{pH}$ dependence of $\mathrm{Mg}^{2+}$ binding as presented in Fig. 6 supports the proposal that one or more amino acids with a negatively charged side chain at physiological buffer $\mathrm{pH}$ are part of the binding domain for the cation.

All observations presented here, together with the recent proposals from the Ca-ATPase [24] and from 19 $\mathrm{kDa}$ membranes [35], support the concept that binding of $\mathrm{Na}^{+}$or $\mathrm{K}^{+}$(or its congeners) to one of the ion sites is competitively blocked by $\mathrm{Mg}^{2+}$ (or other divalent cations), which is assumed to bind close to the entrance port that is formed at least in part by the cytoplasmic loop L6/7 [3, 35]. According to the scheme in Fig. 9A applied for the simulation of the $\mathrm{Na}^{+} / \mathrm{Mg}^{2+}$ antagonism the occupation of the " $\mathrm{Mg}^{2+}$ site" would have an influence preferentially on the $\mathrm{Na}^{+}$site with the low affinity $\left(K_{2}^{\mathrm{Na}}\right.$ $=0.85 \mathrm{~mm}$ ).

\section{EFFECTS OF $\mathrm{Br}_{2}$-Titu ${ }^{3+}$}

The observed interaction between $\mathrm{Na}^{+}$and $\mathrm{Br}_{2}-\mathrm{Titu}^{3+}$ (Fig. 7) could be simulated also by the mechanism of competitive binding of both cations at the same site. Reproduction of the concentration dependence of the fluorescence change and half-saturating $\mathrm{Na}^{+}$concentrations, $K^{\mathrm{Na}}$, was possible only without introduction of a mixed state, such as $\mathrm{Br}_{2}-\mathrm{Titu}^{3+} \cdot \mathrm{NaE}_{1}$. Thus either $\mathrm{Na}^{+}$or $\mathrm{Br}_{2}-$ Titu bind to the pump. Exclusive binding of one ion species could be achieved by one of the following mechanisms: Binding of $\mathrm{Br}_{2}-\mathrm{Titu}^{3+}$ could completely block the access of $\mathrm{Na}^{+}$to its sites and binding of $\mathrm{Na}^{+}$ prevents binding of the blocking ion by steric reasons, by Coulomb repulsion or effects of protein conformation. The differences in kinetics which were found to describe the antagonistic effects of $\mathrm{Na}^{+}$and divalent cations as well as the large organic $\mathrm{Br}_{2}-\mathrm{Titu}^{3+}$ has to be scrutinized with respect to its significance in future experiments.

\section{CONCLusions}

The interaction of various cations with the cytoplasmic binding sites of the $\mathrm{Na}, \mathrm{K}$-ATPase as presented in this paper can be reproduced essentially on the basis of the reaction scheme shown in Fig. 9A. The concentration dependence of ion binding and of mutual effects between ion species is controlled exclusively by the specific equilibrium dissociation constants of the ion sites accessible. Three different sites could be discriminated. The first one is either identical or spatially very close to the binding site for di- or trivalent cations so that all cations compete at this site for binding. It is assumed that the cytoplasmic loop L6/7 with its negatively charged aspar- tate and glutamate residues affect access and binding of the cations. The binding affinity of this "first site" was found to be highest for $\mathrm{Br}_{2}-\mathrm{Titu}^{3+}\left(<\mu \mathrm{M}\right.$, Fig. 7). $\mathrm{Ca}^{2+}$ binds tighter than $\mathrm{Mg}^{2+}$ (Fig. 3), and $\mathrm{Mg}^{2+}$ has approximately the same affinity as $\mathrm{Na}^{+}(0.5 \mathrm{mM} v s .0 .85 \mathrm{~mm})$. The part of the site which binds alkali ions has to be shaped rather rigidly to exhibit such a high selectivity as shown in Fig. 8, where $\mathrm{K}^{+}$and $\mathrm{Rb}^{+}$have the highest affinity for this site. In the binding sequence of $\mathrm{Na}^{+}$this site would be related to the second ion bound. The first $\mathrm{Na}^{+}$ion is assumed to bind to a site formed by transmembrane $\alpha$-helices (which could be M4-M6 and M8 according to [37]). In the case of Na,K-ATPase this site is not accessible for di- or trivalent cations. The first two sites have to be situated close to the cytoplasmic interface of the ion pump since ion binding to these sites is not electrogenic. As a mechanistic concept it could be proposed that when two $\mathrm{K}^{+}$ions (or its congeners) are bound these ions become occluded, accompanied by a movement of the L6/7 loop, and due to their tight fit the pump immediately undergoes the conformational transition into state $\mathrm{E}_{2}\left(\mathrm{~K}_{2}\right)$. When two $\mathrm{Na}^{+}$ions are bound to these sites they are (pre-)occluded; however, a transition into an $E_{2}$ state is either not stable or not possible, but the third (cytoplasmic) ion binding site becomes accessible in the (then preserved) $E_{1}$ state, which is exclusively selective for $\mathrm{Na}^{+}$and has a higher binding affinity than the second $\mathrm{Na}^{+}$site. Even though a $\mathrm{Mg}^{2+}$ ion is bound to the unspecific site a $\mathrm{Na}^{+}$ion can bind to its high-affinity site; thus producing the mixed state, $\mathrm{MgNaE}_{1}$, which is essential for the observed binding kinetics (Fig. 9). In contrast, if the unspecific site is occupied by $\mathrm{Br}_{2}$-Titu the mixed state, $\mathrm{Br}_{2}$-Titu $\cdot \mathrm{NaE}_{1}$, seemed to be kinetically inhibited, since the interaction of both ions could be described perfectly with the linear reaction sequence shown in Fig. $7 B$. The third binding site is placed inside the protein dielectric (about 25\%), is uncharged, exclusively selective for $\mathrm{Na}^{+}$, and binding to this site promotes a conformational relaxation that is propagated, possibly by another movement of the L6/7 loop [32, 37], to the nucleotide binding site where Asp372 becomes competent to be phosphorylated by ATP [12, 30, 31].

We thank Milena Roudna for excellent technical assistance. This work was financially supported by the Deutsche Forschungsgemeinschaft (Ap 45/4) and by INTAS (Project 96-1310).

\section{References}

1. Albers, R.W. 2000. Biochemical aspects of active transport. Ann. Rev. Biochem. 36:727-756

2. Apell, H.-J. 1998. Kinetic and energetic aspects of $\mathrm{Na}^{+} / \mathrm{K}^{+}$transport cycle steps. Ann. N.Y. Acad. Sci. 834:221-230

3. Apell, H.-J., Karlish, S.J.D. 2001. Functional properties of Na,KATPase, and their structural implications, as detected with biophysical techniques. J. Membrane Biol. 801:1-9

4. Apell, H.-J., Roudna, M., Corrie, J.E., Trentham, D.R. 1996. Kinetics of the phosphorylation of Na,K-ATPase by inorganic phos- 
phate detected by a fluorescence method. Biochemistry 35:1092210930

5. Bahinski, A., Nakao, M., Gadsby, D.C. 1988. Potassium translocation by the $\mathrm{Na}^{+} / \mathrm{K}^{+}$pump is voltage insensitive. Proc. Natl. Acad. Sci. USA 85:3412-3416

6. Borlinghaus, R., Apell, H.-J., Läuger, P. 1987. Fast charge translocations associated with partial reactions of the Na,K-pump: I. Current and voltage transients after photochemical release of ATP. J. Membrane Biol. 97:161-178

7. Bühler, R., Stürmer, W., Apell, H.-J., Läuger, P. 1991. Charge translocation by the Na,K-pump: I. Kinetics of local field changes studied by time-resolved fluorescence measurements. J. Membrane Biol. 121:141-161

8. Campos, M., Beaugé, L. 1994. $\mathrm{Na}^{+}$-ATPase activity of $\mathrm{Na}^{+}, \mathrm{K}^{+}$ATPase. J. Biol. Chem. 269:18028-18036

9. Capasso, J.M., Hoving, S., Tal, D.M., Goldshleger, R., Karlish, S.J.D. 1992. Extensive digestion of $\mathrm{Na}^{+}, \mathrm{K}^{+}$-ATPase by specific and nonspecific proteases with preservation of cation occlusion sites. J. Biol. Chem. 267:1150-1158

10. Clarke, R.J., Kane, D.J., Apell, H.-J., Roudna, M., Bamberg, E. 1998. Kinetics of $\mathrm{Na}^{+}$-dependent conformational changes of rabbit kidney $\mathrm{Na}^{+}, \mathrm{K}^{+}$-ATPase. Biophys. J. 75:1340-1353

11. Cornelius, F. 1999. Rate determination in phosphorylation of shark rectal Na,K-ATPase by ATP: temperature sensitivity and effects of ADP. Biophys. J. 77:934-942

12. Domaszewicz, W., Apell, H.-J. 1999. Binding of the third $\mathrm{Na}^{+}$ion to the cytoplasmic side of the Na,K-ATPase is electrogenic. FEBS Lett. 458:241-246

13. Düzdünes, N., Papahadjopoulos, D. 1983. Iontrophic effects on phospholipid membranes: calcium magnesium specificity binding, fluidity and fusion. In: Membrane Fluidity in Biology. R.C. Aloia, editor. pp. 187-216. Academic Press, New York

14. Gache, C., Rossi, B., Leone, F.A., Lazdunski, M. 1979. Pseudosubstrates to analyze the reaction mechanism of the Na,K-ATPase. In: Na.K-ATPase Structure and Kinetics. J.C. Skou and J.G. Nørby, editors. pp. 301-314. Academic Press, London

15. Heyse, S., Wuddel, I., Apell, H.-J., Stürmer, W. 1994. Partial reactions of the Na,K-ATPase: determination of rate constants. $J$. Gen. Physiol. 104:197-240

16. Hilgemann, D.W. 1994. Channel-like Function of the Na,K Pump Probed at Microsecond Resolution in Giant Membrane Patches. Science 263: 1429-1432

17. Holmgren, M., Wagg, J., Bezanilla, F., Rakowski, R.F., de Weer, P., Gadsby, D.C. 2000. Three distinct and sequential steps in the release of sodium ions by the $\mathrm{Na}^{+} / \mathrm{K}^{+}$-ATPase. Nature 403:898901

18. Hoving, S., Bar-Shimon, M., Tijmes, J.J., Goldshleger, R., Tal, D.M., Karlish, S.J. 1995. Novel aromatic isothiouronium derivatives which act as high affinity competitive antagonists of alkali metal cations on Na/K-ATPase. J. Biol. Chem. 270:29788-29793

19. Jørgensen, P.L. 1974. Isolation of $\left(\mathrm{Na}^{+}+\mathrm{K}^{+}\right)$-ATPase. Meth. Enzymol. 32:277-290

20. Jørgensen, P.L. 1992. Na,K-ATPase, structure and transport mechanism. In: Molecular Aspects of Transport Proteins. J.J.H.H.M. de Pont, editor. pp. 1-26. Elsevier Science Publishers, Amsterdam

21. Karlish, S.J.D. 1980. Characterization of conformational changes in $(\mathrm{Na}, \mathrm{K})$ ATPase labeled with fluorescein at the active site. $J$. Bioenerg. Biomembr. 12:111-136

22. Läuger, P. 1991. Electrogenic Ion Pumps. Sinauer, Sunderland, MA

23. Matsui, H., Homareda, H., Hayashi, Y. 1985. Characteristics of $\mathrm{Na}^{+}$and $\mathrm{K}^{+}$binding to Na,K-ATPase. In: The Sodium Pump. I.
Glynn and O. Ellroy, editors. pp. 243-249. The Company of Biologists, Cambridge

24. Menguy, T., Corre, F., Bouneau, L., Deschamps, S., Moller, J.V., Champeil, P., le Maire, M., Falson, P. 1998. The cytoplasmic loop located between transmembrane segments 6 and 7 controls activation by $\mathrm{Ca}^{2+}$ of sarcoplasmic reticulum $\mathrm{Ca}^{2+}$-ATPase. J. Biol. Chem. 273:20134-20143

25. Or, E., Goldshleger, R., Karlish, S.J.D. 1996. An effect of voltage on binding of $\mathrm{Na}^{+}$at the cytoplasmic surface of the $\mathrm{Na}^{+}-\mathrm{K}^{+}$pump. J. Biol. Chem. 271:2470-2477

26. Pintschovius, J., Fendler, K., Bamberg, E. 1999. Charge translocation by the $\mathrm{Na}^{+} / \mathrm{K}^{+}$-ATPase investigated on solid supported membranes: Cytoplasmic cation binding and release. Biophys. J. 76:827-836

27. Post, R.L., Kume, S., Tobin, T., Orcutt, B., Sen, A.K. 1969. Flexibility of an active center in sodium-plus-potassium adenosine triphosphatase. J. Gen. Physiol. 54:306s-326s

28. Post, R.L., Toda, G., Rogers, F.N. 1975. Phosphorylation by inorganic phosphate of sodium plus potassium ion transport adenosine triphosphatase. J. Biol. Chem. 250:691-701

29. Post, R.L., Toda, G., Rogers, F.N. 1975. Phosphorylation by inorganic phosphate of sodium plus potassium ion transport adenosine triphosphatase. Four reactive states. J. Biol. Chem. 250:691-701

30. Schneeberger, A., Apell, H.-J. 1999. Ion selectivity of the cytoplasmic binding sites of the Na,K-ATPase: I. Sodium binding is associated with a conformational rearrangement. J. Membrane Biol. 168:221-228

31. Schneeberger, A., Apell, H.-J. 2000. Properties of the Sodiumpump ion binding sites in state $\mathrm{E}_{1}$. In: $\mathrm{Na} / \mathrm{K}$-ATPase and Related Pumps. K. Taniguchi, and S. Kaya, editors. Elsevier Science B.V., Amsterdam

32. Schulz, S., Apell, H.-J. 1995. Investigation of ion binding to the cytoplasmic binding sites of the Na,K-pump. Eur. Biophys. J. 23:413-421

33. Schwappach, B., Stürmer, W., Apell, H.-J., Karlish, S.J.D. 1994. Binding of sodium ions and cardiotonic steroids to native and selectively trypsinized $\mathrm{Na}, \mathrm{K}$ pump, detected by charge movements. J. Biol. Chem. 269:21620-21626

34. Schwartz, A.K., Nagano, M., Nakao, M., Lindenmayer, G.E., Allen, J.C. 1971. The sodium- and potassium-activated adenosinetriphosphatase system. Meth. Pharmacol. 1:361-388

35. Shainskaya, A., Schneeberger, A., Apell, H.-J., Karlish, S.J. 2000. Entrance port for $\mathrm{Na}^{+}$and $\mathrm{K}^{+}$ions on $\mathrm{Na}^{+}, \mathrm{K}^{+}$-ATPase in the cytoplasmic loop between transmembrane segments M6 and M7 of the alpha subunit. Proximity of the cytoplasmic segment of the beta subunit. J. Biol. Chem. 275:2019-2028

36. Tanford, C., Reynolds, J.A., Johnson, E.A. 1987. Sarcoplasmatic reticulum calcium pump: A model for $\mathrm{Ca}^{2+}$ binding and $\mathrm{Ca}^{2+}$ coupled phosphorylation. Proc. Natl. Acad. Sci. USA 84:70947098

37. Toyoshima, C., Nakasako, M., Nomura, H., Ogawa, H. 2000. Spatial structure of the calcium pump of sarcoplasmatic reticulum at $2.6 \AA$ resolution. Nature 405:647-655

38. Vilsen, B. 1995. Structure-function relationships in the $\mathrm{Ca}^{2+}$ ATPase of sarcoplasmic reticulum studied by use of the substrate analogue CrATP and site-directed mutagenesis. Comparison with the $\mathrm{Na}^{+}, \mathrm{K}^{+}$-ATPase. Acta Physiol. Scand. Suppl. 624:1-146

39. Vilsen, B., Ramlov, D., Andersen, J.P. 1997. Functional consequences of mutations in the transmembrane core region for cation translocation and energy transduction in the $\mathrm{Na}^{+}, \mathrm{K}^{+}$-ATPase and the SR Ca ${ }^{2+}$-ATPase. Ann. N.Y. Acad. Sci. 834:297-309

40. Wuddel, I., Apell, H.-J. 1995. Electrogenicity of the sodium transport pathway in the Na,K-ATPase probed by charge-pulse experiments. Biophys. J. 69:909-921 